\title{
A Comparative Cytotoxic Evaluation of Acrylamide and Diacetone Acrylamide to Investigate Their Suitability for Holographic Photopolymer Formulations
}

\author{
Dervil Cody, ${ }^{1,2}$ Alan Casey, ${ }^{2,3}$ Izabela Naydenova, ${ }^{1,2}$ and Emilia Mihaylova ${ }^{1,2,4}$ \\ ${ }^{1}$ Centre for Industrial and Engineering Optics, Dublin Institute of Technology, Dublin 8, Ireland \\ ${ }^{2}$ School of Physics, College of Sciences and Health, Dublin Institute of Technology, Dublin 8, Ireland \\ ${ }^{3}$ Nanolab Research Centre, FOCAS, Dublin Institute of Technology, Camden Row, Dublin 8, Ireland \\ ${ }^{4}$ Department of Mathematics and Physics, Agricultural University, 4000 Plovdiv, Bulgaria \\ Correspondence should be addressed to Emilia Mihaylova; emilia.mihaylova@dit.ie
}

Received 30 May 2013; Accepted 1 August 2013

Academic Editor: Zhou Yang

Copyright (C) 2013 Dervil Cody et al. This is an open access article distributed under the Creative Commons Attribution License, which permits unrestricted use, distribution, and reproduction in any medium, provided the original work is properly cited.

\begin{abstract}
The comparative cytotoxic evaluation of two monomers, diacetone acrylamide (DA) and acrylamide (AA) used in holographic photopolymer formulations, is reported. Two normal cell lines were used: BEAS-2B and HaCaT. Cellular viability was assessed using the MTT assay for three different exposure times. A difference of two orders of magnitude is observed in the lethal dose (LD50) concentrations of the two monomers. Diacetone acrylamide exhibits a significantly lower toxicity profile in comparison to acrylamide at all exposure times. This result justifies the replacement of acrylamide with diacetone acrylamide in the photopolymer formulation, with the view to reducing occupational hazard risks for large-scale holographic device fabrication. A comparative study investigating the holographic recording ability of the two photopolymers in transmission mode showed that the DA photopolymer is capable of reaching refractive index modulation values of $3.3 \times 10^{-3}$, which is $80 \%$ of the refractive index modulation achieved by the AA photopolymer. This makes the DA-based photopolymers suitable for a wide range of applications.
\end{abstract}

\section{Introduction}

Photopolymer materials are widely researched for a variety of holographic applications such as diffractive optics and holographic data storage. One of the most promising new applications in recent years is the development of "smart holograms" for use as biosensors [1-8]. Holographic photopolymers have so far been used in the development of sensors which monitor changes in the relative humidity and temperature of their environment, as well as sensors which respond to the presence of toxic gases such as toluene [912]. Acrylamide (AA), a main component of the standard photopolymer composition, is carcinogenic and toxic in its monomer form. This toxicity has been extensively investigated, using both in vivo and in vitro methods [13-19]. An extensive study into the chemical and biochemical safety of AA carried out by Friedman [20] found that AA is involved in reactions with proteins such as haemoglobin, enzymes, and
DNA. A recent development has been the replacement of AA with a nontoxic monomer diacetone acrylamide (DA) in the photopolymer composition [21, 22]. This has been done to reduce the potential occupational and environmental hazards involved in future large-scale material development and device fabrication. The new material's holographic recording capability has already been shown to surpass that of other reported low-toxicity photopolymer alternatives [23-26].

A comparative study into the in vitro cytotoxicity of DA and AA has been carried out. Two immortalised noncarcinogenic human cell lines were employed for the evaluation, namely, BEAS-2B, a normal bronchial epithelial cell line, and $\mathrm{HaCaT}$, a normal dermal keratinocyte. These cell lines were chosen as they reflect inhalation and dermal exposure routes, thought to be the most likely routes of exposure, in particular for production on a large scale. For cytotoxic evaluation the 3(4,5-dimethylthiazol-2-yl)-2,5-diphenyltetrazolium bromide (MTT) assay (Sigma Aldrich) was used [27, 28]. To the best 


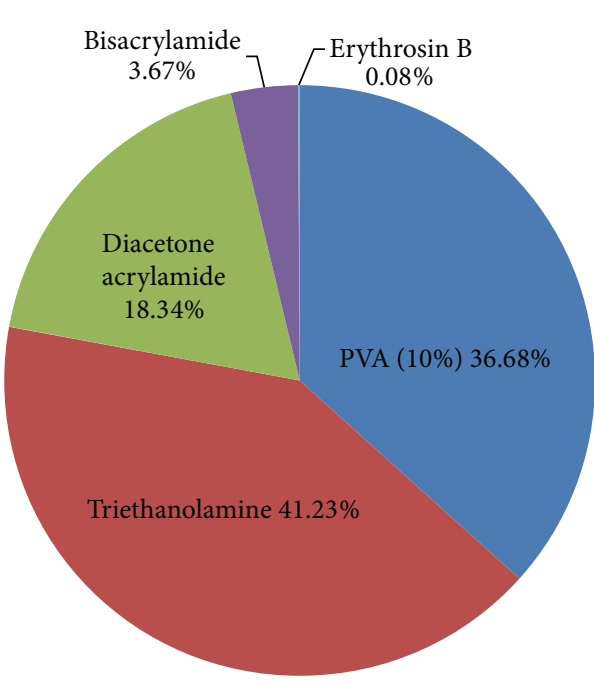

(a)

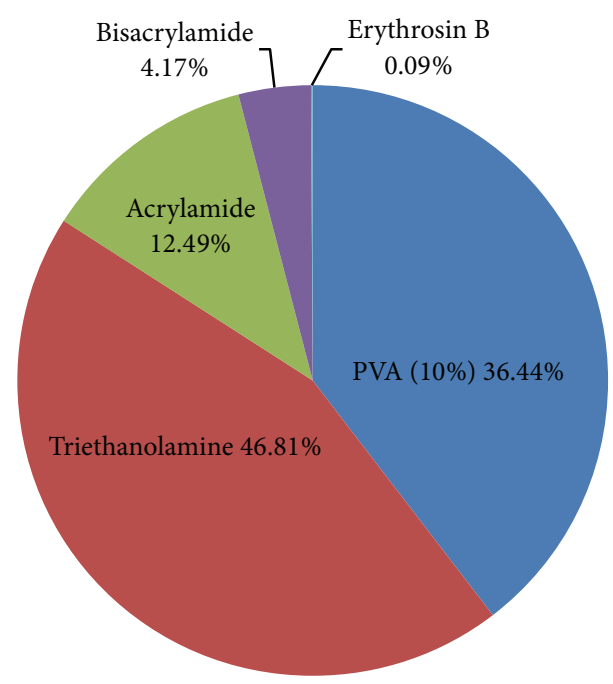

(b)

FIGURE 1: Pie chart representations of the composition of the DA and AA photopolymers.

of the authors' knowledge this is the first time an evaluation has been carried out of the cytotoxicity of the DA monomer.

While reduced toxicity is obviously favourable, it is worthless unless the DA photopolymer can achieve a holographic recording ability that is comparable to the AA photopolymer, which has been extensively characterised [2933], and so be suitable for holographic applications. Therefore it is essential to evaluate the capability of the two monomers for holographic recording at the same conditions. Here, holographic transmission gratings have been recorded in the AA and DA photopolymers over a range of recording intensities. This will allow direct comparison to be made for the first time between the holographic recording ability of the two materials and therefore the effect of the monomer substitution.

\section{Materials and Methods}

2.1. Cell Culture. HaCaT cells were cultured in a DMEMF12 (Gibco) medium supplemented with $10 \%$ foetal bovine serum (FBS). The BEAS-2B cells were cultured in a $10 \% \mathrm{FBS}-$ supplemented RPMI-1640 (GIbco) medium. Both media were supplemented with additional $2 \mathrm{mM}$ L-glutamine (Gibco), $45 \mathrm{IU} / \mathrm{mL}$ penicillin (Gibco), and $45 \mathrm{IU} / \mathrm{mL}$ Streptomycin (Gibco). The cells cultured in a humidified incubator at $37^{\circ} \mathrm{C}\left(5 \% \mathrm{CO}_{2}\right)$.

For cytotoxic evaluation cells were seeded in 96-well plates (Corning) at a density of $1 \times 10^{5}$ cells $/ \mathrm{mL}$ for 24 hour exposures, $5 \times 10^{4}$ cells/mL for 48 -hour exposures and $4 \times 10^{4}$ for 72 -hour exposures. For all experiments and timepoints a minimum of three independent experiments were performed.

2.2. Test Compound Preparation. 10\% wt/vol solutions of the DA and AA monomer compounds were prepared in supplemented media aseptically. The solutions were sonicated for 10-15 minutes to ensure that the monomers are completely dissolved and then sterile filtered. The $\mathrm{HaCaT}$ and BEAS-2B cells were exposed to the test compounds at dose concentrations of $0.0078,0.0156,0.03125,0.0625,0.125$, $0.25,0.5$, and $1.0 \mathrm{mg} / \mathrm{mL}$. The monomer concentration in the bulk DA photopolymer solution is $38.46 \mathrm{mg} / \mathrm{mL}$, while for the AA photopolymer solution the monomer concentration is $24.49 \mathrm{mg} / \mathrm{mL}$. The test concentrations represent the concentration of monomer that would more likely be absorbed by the skin or inhaled through exposure. Both positive $(10 \%$ dimethyl sulfoxide (DMSO)) and negative (media) controls were employed on all replicate and independent plates at all the tested timepoints.

2.3. Cytotoxicity Studies. After the required exposure time had elapsed, the test compound was removed and the cells were rinsed with PBS. $100 \mu \mathrm{L}$ of freshly prepared MTT dye $(0.25 \mathrm{mg} / \mathrm{L})$ in unsupplemented media solution was then added to each well. The plates were incubated for three hours to allow the reduction of the soluble, yellow tetrazolium salt into an insoluble, purple formazan precipitate. Plates were then again rinsed with $100 \mu \mathrm{L}$ of PBS; finally $100 \mu \mathrm{L}$ of DMSO was added to each well to solubilise the purple precipitate. The plates were then shaken at $240 \mathrm{rpm}$ for 15 minutes. The absorbance and hence the cell viability for each concentration dose were then measured at $540 \mathrm{~nm}$ using a microplate reader. Control values were set as $100 \%$. Differences between compounds and the control were evaluated using the statistical analysis package SPSS 14.0. Statistically significant differences were set at $P<0.01$. Normality of data was confirmed with Q-Q percentile plots and Kolmogorov-Smirnov tests. Equality of variances was evaluated using Levène's tests. Oneway analysis of variances (ANOVA) followed by Dunnett's multiple comparison tests was carried out for normally distributed samples with homogeneous variances. Cytotoxicity data was fitted to a sigmoidal curve and a four-parameter nonlinear logistic model used to calculate the lethal dose of test compound that caused a $50 \%$ inhibition in comparison to 


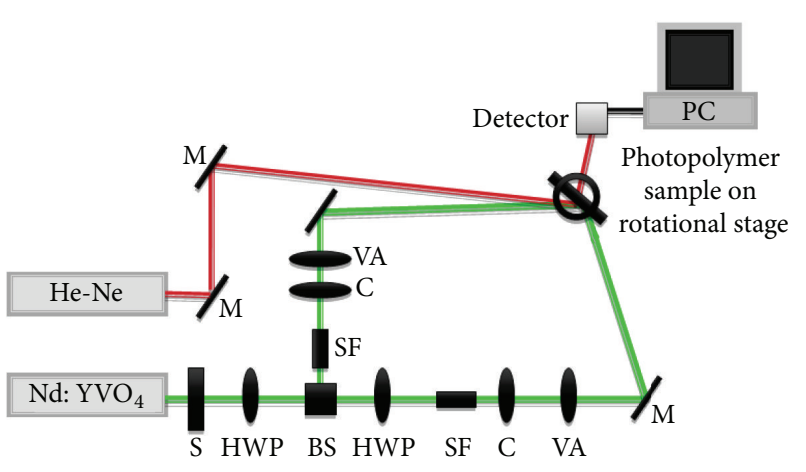

FIGURE 2: Experimental setup. S: shutter, HWP: half wave plate, BS: polarising beam splitter, SF: spatial filter, C: collimator, VA: variable aperture, M: mirror.

untreated controls (LD50). All LD50 values were calculated using the average cytotoxicity data of the three independent experimental results and their associated errors. LD50 values are reported with $\pm 95 \%$ confidence intervals $( \pm 95 \% \mathrm{CI})$. Lethal dose 50 (LD50) values were estimated using Xlfit3, a curve fitting add-on for Microsoft_Excel (ID Business Solutions, UK).

\subsection{Sample Preparation for Holographic Characterisation} Study. The DA and AA photopolymer compositions were prepared as shown in Figure 1. The photopolymer solution was then deposited onto glass slides $(76 \times 26 \mathrm{~mm})$ and allowed to dry for 12-24 hours in darkness under normal laboratory conditions $\left(20-25^{\circ} \mathrm{C}, 40-60 \% \mathrm{RH}\right)$. Layer thickness was measured using a white-light surface profiler (Micro XAM S/N 8038) and was found to be $60 \pm 10 \mu \mathrm{m}$.

2.5. Holographic Recording Setup. A two-beam holographic optical setup (see Figure 2) with an angle of $30.85^{\circ}$ between the beams was used to record unslanted transmission gratings, using a $532 \mathrm{~nm}$ vertically polarised $\mathrm{Nd}: \mathrm{YVO} 4$ laser. Gratings were recorded in the layers for an exposure energy of $100 \mathrm{~mJ} / \mathrm{cm}^{2}$ at a spatial frequency of $1000 \pm 10 \mathrm{lines} / \mathrm{mm}$. The absorption of the photopolymer at $633 \mathrm{~nm}$ is negligible, so a $633 \mathrm{~nm}$ He-Ne laser was used as the probe beam at the Bragg angle. As the recorded gratings are isotropic in nature, their diffraction efficiency is not dependent on the polarisation of the probe beam. An optical power meter (Newport 1830-C) was used to record the intensity of the diffracted beam, and LabVIEW software was used to plot the data in real time. In order to measure the diffracted intensity dependence on the incident angle of the probe beam, the grating was placed on a rotational stage (Newport ESP 300). The accuracy of this measurement was $1 \times 10^{-3} \mathrm{deg}$.

These parameters allow for application of Kogelnik's coupled-wave theory for volume, thick gratings [34], which is used here to determine refractive index modulation $(\Delta n)$ of the recorded gratings:

$$
\Delta n=\frac{\lambda \cos \theta \sin ^{-1}(\sqrt{\eta})}{\pi d},
$$

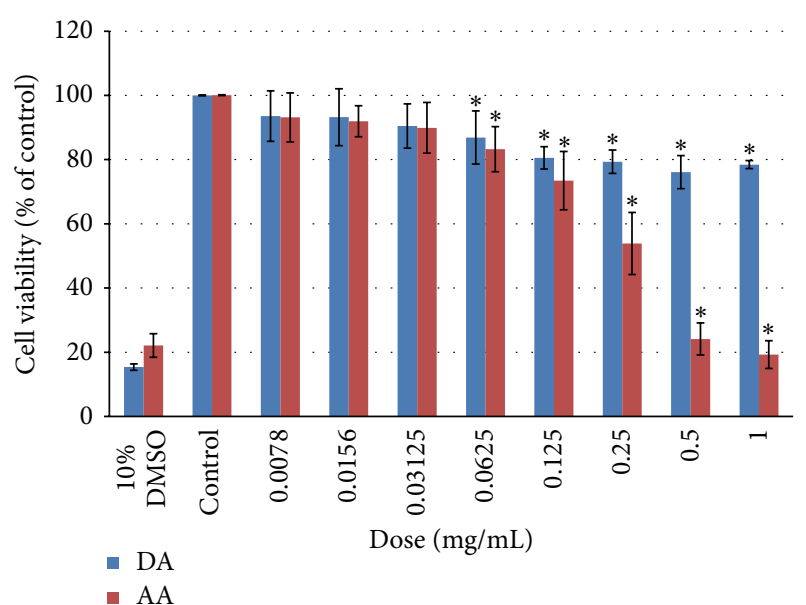

Figure 3: Cellular viability versus monomer dose for the BEAS2B cells for a 24-hour exposure. Data is expressed as an average of three independent experiments \pm standard deviation for each independent experiment. “*” denotes a statistically significant $(P<$ 0.01) difference from the unexposed control.

where $\theta, \lambda$ are the reconstruction beam incident angle and wavelength. $\eta$ is the diffraction efficiency of the recorded grating (defined here as the ratio of the intensity of the first diffraction order and the incident intensity of the probe beam) and $d$ is the thickness of the photosensitive layer.

\section{Results and Discussion}

3.1. Cell Viability versus Monomer Dose. The cellular viability was expressed as a percentage of the negative control for each concentration dose, for both the DA and AA compounds at all three exposure times. A sample of the results is shown in Figure 3. The cell viability versus monomer dose for the BEAS-2B cells exposed for 24 hours is presented. The cell viability is significantly decreased by $80 \%$ as the AA monomer concentration is increased from none to $1 \mathrm{mg} / \mathrm{mL}$. The cell death is considerably greater for AA than that for DA, for which the cell viability decreases by $20 \%$ only over the same range of dose concentrations. A similar trend was observed for both cell lines and all exposure times. These results corroborate the AA effect observed by Ma et al. [13].

3.2. LD50 Comparison. The LD50 value, or lethal dose value, is the monomer dose concentration at which the cellular viability is reduced by $50 \%$ [35]. Table 1 shows the LD50 values calculated for each exposure time for the two monomers, for the two different cell lines. For the HaCaT line, there is an order of magnitude difference in the LD50 values between $\mathrm{AA}$ and DA for all exposures. For the BEAS-2B line, the difference is even more considerable. The LD50 values for the DA monomer are two orders of magnitude larger than those for AA.

The significant difference in LD50 values between the DA and AA monomer for the two cell lines may be attributed to the fact that the dermal skin line is by nature more robust 
TABLE 1: LD50 values for the DA and AA monomers for 24-, 48- and 72-hour exposures for the $\mathrm{HaCaT}$ and BEAS-2B cellular lines.

\begin{tabular}{lccc}
\hline & $\begin{array}{c}\text { LD50 24 HR } \\
(\mathrm{mg} / \mathrm{mL})\end{array}$ & $\begin{array}{c}\text { LD50 48 HR } \\
(\mathrm{mg} / \mathrm{mL})\end{array}$ & $\begin{array}{c}\mathrm{LD5072} \mathrm{HR} \\
(\mathrm{mg} / \mathrm{mL})\end{array}$ \\
\hline HaCaT & & & \\
DA monomer & 4.78 & 3.92 & 3.55 \\
AA monomer & 0.5 & 0.17 & 0.12 \\
BEAS-2B & & & \\
DA monomer & 38.49 & 21.48 & 7.25 \\
AA monomer & 0.26 & 0.11 & 0.06 \\
\hline
\end{tabular}

than the bronchial cell line. However there are several other factors which may contribute to the difference in toxicity of the AA and DA monomers, the first of which is the size of the monomer molecules. As shown in Figure 4, the AA molecules are smaller in size than the DA molecules. Therefore the AA molecules may more easily permeate the cell membrane by passive diffusion or through aqueous pores [36]. In addition to that previous studies suggest that hydrogen-bonding interactions between the $\mathrm{CONH}_{2}$ part of the AA molecule and cell membrane components may enhance the monomers ability to alter cell membrane structures and accelerate its diffusion and penetration [20]. A second factor is the number of molecules available at the tested concentrations. Using the molecular weights of the two monomers, the ratio of the number of AA: DA molecules is calculated to be $2.4: 1$. This means that a higher number of AA molecules are available to cause cell death. Thirdly, there are a higher number of smaller AA molecules compared to a lower number of larger DA molecules. When comparing the cytotoxic effect of the two monomers at the same concentration, a high number of smaller molecules as in the case of AA is favourable for interaction with cells as it results in an increase in the overall surface area. This makes an interaction more likely to occur [37]. Also, the reactive site may be blocked by another part of the molecule, such as the large group in the case of the DA molecule.

Future work will include detailed studies to identify the mechanism responsible for cell death and to determine the principle differences in the DA and AA monomers toxicological properties.

3.3. Holographic Characterisation Study. Transmission gratings were recorded in the DA and AA photopolymer layers using a recording intensity which was varied from 1 to $5 \mathrm{~mW} / \mathrm{cm}^{2}$, with constant exposure energy of $100 \mathrm{~mJ} / \mathrm{cm}^{2}$. Shown in Figure 5 are typical real-time diffraction efficiency growth curve and angular selectivity curve obtained for the DA material. The diffraction efficiency of the recorded grating remains constant after the laser is switched off. Figure 6 shows the $\Delta n$ versus recording intensity for holographic gratings recorded in the DA and AA photopolymers. The DA photopolymer achieves a maximum $\Delta n$ of $3.3 \times 10^{-3}$ for a recording intensity of $2 \mathrm{~mW} / \mathrm{cm}^{2}$. The AA photopolymer reaches its maximum $\Delta n$ of $4.1 \times 10^{-3}$

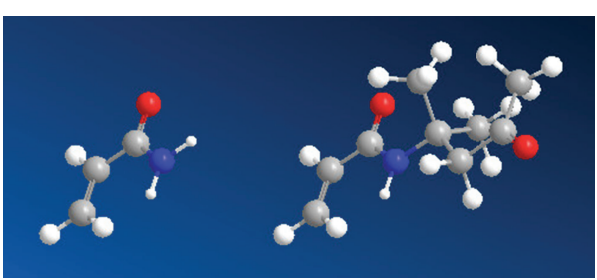

FIgURE 4: 3D representation of the molecular structure of the AA $\left(\mathrm{CH}_{2}=\mathrm{CHCONH}_{2}\right)$ and DA $\left(\mathrm{CHCONHC}\left(\mathrm{CH}_{3}\right)_{2} \mathrm{CH}_{2} \mathrm{COCH}_{3}\right)$ molecules.

for an intensity of $4 \mathrm{~mW} / \mathrm{cm}^{2}$. Therefore the $\Delta n$ of the DA photopolymer is $80 \%$ of that achieved with the AA photopolymer. These results show that the DA material is sensitive enough for holographic applications and devices, such as sensors.

The optimum recording intensity for the AA photopolymer is twice as high as for the DA photopolymer. In order to explain this, the basic mechanism behind grating formation in photopolymers must be described. The two main processes which govern hologram formation are polymerisation of monomers and diffusion. The ratio of the polymerisation rate to the diffusion rate is an important factor [38]. The rate of polymerisation is proportional to the recording intensity used. If the polymerisation rate is very fast, as is the case at higher recording intensities, the diffusion rate must be fast also in order to facilitate the movement of the monomer molecules from dark to bright regions, so that they can be polymerised. If this is not the case, then $\Delta n$ will be reduced as a result.

The DA monomer molecules are larger in size, and thus they diffuse at a slower rate compared to the AA monomer molecules. Therefore for the DA monomer lower recording intensities will be optimum, as polymerisation must proceed at a slower rate in order to facilitate slower diffusion. The AA molecules are restricted less due to their smaller size and so can diffuse quickly enough to be polymerised at the higher recording intensities.

\section{Conclusion}

The cytotoxicity of the DA and AA monomers has been investigated for two human cell lines. It is shown that DA exhibits a significantly lower toxicity profile than AA for both the dermal and bronchial cell lines, with up to two orders of magnitude difference in the LD50 concentration doses evaluated. This justifies the replacement of AA with DA with the view to reducing occupational hazard risks for large-scale holographic device fabrication. Characterisation of the holographic recording ability of the two photopolymers in transmission mode shows that the DA photopolymer achieves $\Delta n$ values of $3.3 \times 10^{-3}$, which is $80 \%$ of that of the AA photopolymer, and therefore is sensitive enough for most holographic applications and devices. Further research will be carried out into the suitability of the photopolymer material for environmental and biosensor applications. 


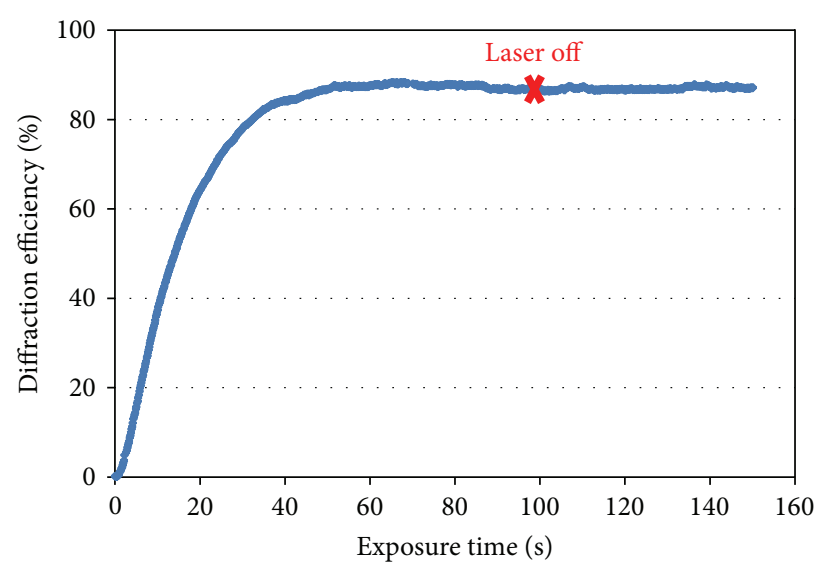

(a)

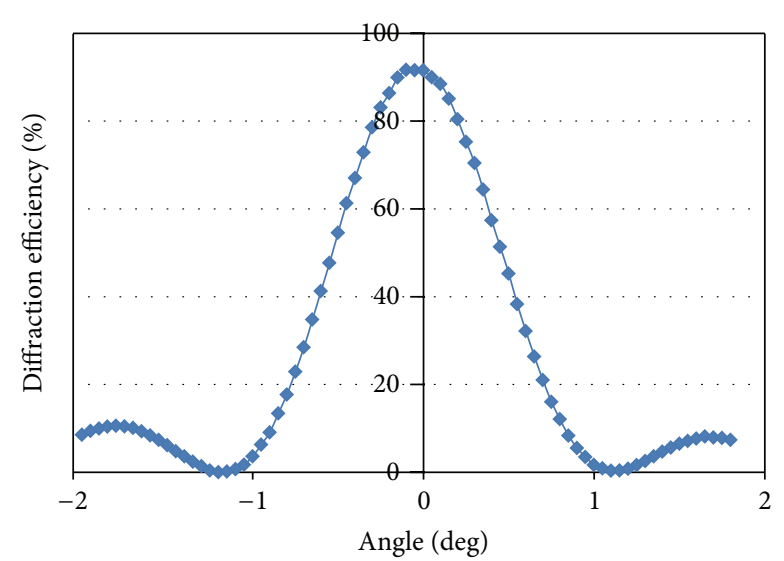

(b)

FIGURE 5: (a) Real-time diffraction efficiency growth curve for a $60 \pm 10 \mu \mathrm{m}$ DA photopolymer layer exposed to a total recording intensity of $2 \mathrm{~mW} / \mathrm{cm}^{2}$. (b) Diffraction efficiency versus incident angle of probe beam.

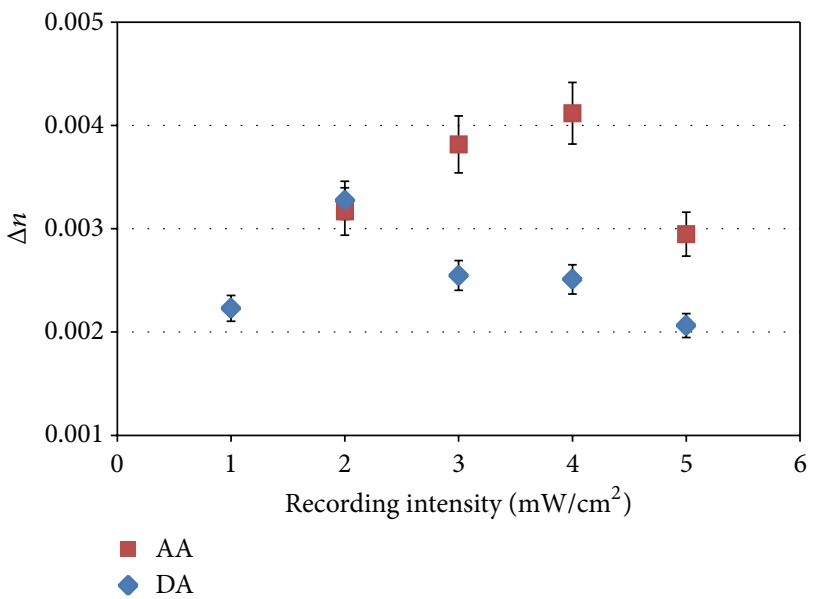

FIGURE 6: $\Delta n$ versus recording intensity for the DA and AA photopolymers at a spatial frequency of $1000 \mathrm{~L} / \mathrm{mm}$ in $60 \pm 10 \mu \mathrm{m}$ thick layers. The total exposure energy was kept constant at $100 \mathrm{~mJ} / \mathrm{cm}^{2}$. Data is expressed as an average of five $\Delta n$ measurements \pm standard deviation for each $\Delta n$ measurement.

\section{Conflict of Interests}

The authors declare that there is no conflict of interests.

\section{Acknowledgments}

The authors acknowledge the Irish Research Council Embark Initiative for financial support and also thank the FOCAS Research Institute in DIT for providing the research facilities to carry out the experimental work.

\section{References}

[1] Y. Fuchs, O. Soppera, A. G. Mayes, and K. Haupt, "Holographic molecularly imprinted polymers for label-free chemical sensing," Advanced Materials, vol. 25, no. 4, pp. 566-570, 2013.
[2] Y. Fuchs, O. Soppera, and K. Haupt, "Photopolymerization and photostructuring of molecularly imprinted polymers for sensor applications-a review," Analytica Chimica Acta, vol. 717, pp. 720, 2012.

[3] S. Kabilan, A. J. Marshall, A. Horgan et al., "'Smart' hologramsa novel diagnostics platform," in Technical Proceedings of the 2006 NSTI Nanotechnology Conference and Trade Show, vol. 3, pp. 467-470, Boston, Mass, USA, May 2006.

[4] A. J. Marshall, D. S. Young, J. Blyth, S. Kabilan, and C. R. Lowe, "Metabolite-sensitive holographic biosensors," Analytical Chemistry, vol. 76, no. 5, pp. 1518-1523, 2004.

[5] D. Bhatta, G. Christie, B. Madrigal-González, J. Blyth, and C. R. Lowe, "Holographic sensors for the detection of bacterial spores," Biosensors and Bioelectronics, vol. 23, no. 4, pp. 520-527, 2007.

[6] S. Kabilan, A. J. Marshall, F. K. Sartain et al., "Holographic glucose sensors," Biosensors and Bioelectronics, vol. 20, no. 8, pp. 1602-1610, 2005.

[7] X. Yang, X. Pan, J. Blyth, and C. R. Lowe, “Towards the real-time monitoring of glucose in tear fluid: Holographic glucose sensors with reduced interference from lactate and $\mathrm{pH}$," Biosensors and Bioelectronics, vol. 23, no. 6, pp. 899-905, 2008.

[8] R. B. Millington, A. G. Mayes, J. Blyth, and C. R. Lowe, "A hologram biosensor for proteases," Sensors and Actuators B, vol. 33, no. 1-3, pp. 55-59, 1996.

[9] E. Leite, I. Naydenova, S. Mintova, L. Leclercq, and V. Toal, "Photopolymerizable nanocomposites for holographic recording and sensor application," Applied Optics, vol. 49, no. 19, pp. 3652-3660, 2010.

[10] I. Naydenova, R. Jallapuram, V. Toal, and S. Martin, "Characterisation of the humidity and temperature responses of a reflection hologram recorded in acrylamide-based photopolymer," Sensors and Actuators B, vol. 139, no. 1, pp. 35-38, 2009.

[11] I. Naydenova, S. Martin, and V. Toal, "Photopolymers-beyond the standard approach to photosensitisation," Journal of the European Optical Society, vol. 4, Article ID 09042, 2009.

[12] I. Naydenova, R. Jallapuram, V. Toal, and S. Martin, "A visual indication of environmental humidity using a color changing hologram recorded in a self-developing photopolymer," Applied Physics Letters, vol. 92, no. 3, Article ID 031109, 2008. 
[13] X. X. Ma, G. D. Yao, H. Cheng, Q. L. Zeng, and Q. Chen, "Effects of acrylamide on DNA damage in human keratinocytes," Analytical Chemistry, vol. 76, no. 5, pp. 1518-1523, 2004.

[14] J. E. Klaunig and L. M. Kamendulis, "Mechanisms of acrylamide induced rodent carcinogenesis," Advances in Experimental Medicine and Biology, vol. 561, pp. 49-62, 2005.

[15] J. Park, L. M. Kamendulis, M. A. Friedman, and J. E. Klaunig, "Acrylamide-induced cellular transformation," Toxicological Sciences, vol. 65, no. 2, pp. 177-183, 2001.

[16] G. Lawrence, R. Gentry, T. McDonald et al., "Acrylamide: review of toxicity data and dose-response analyses for cancer and noncancer effects," Critical Reviews in Toxicology, vol. 36, no. 6 , pp. 481-608, 2006.

[17] H. Tsuda, C. S. Shimizu, M. K. Taketomi et al., "Acrylamide; induction of DNA damage, chromosomal aberrations and cell transformation without gene mutations," Mutagenesis, vol. 8, no. 1, pp. 23-29, 1993.

[18] K. A. Johnson, S. J. Gorzinski, and K. M. Bodner, "Chronic toxicity and oncogenicity study on acrylamide incorporated in the drinking water of Fischer 344 rats," Toxicology and Applied Pharmacology, vol. 85, no. 2, pp. 154-168, 1986.

[19] T. Takahashi, M. Yoshii, T. Kawano, T. Kosaka, and H. Hosoya, "A new approach for the assessment of acrylamide toxicity using a green paramecium," Toxicology in Vitro, vol. 19, no. 1, pp. 99105, 2005.

[20] M. Friedman, "Chemistry, biochemistry, and safety of acrylamide. A review," Journal of Agricultural and Food Chemistry, vol. 51, no. 16, pp. 4504-4526, 2003.

[21] D. Cody, I. Naydenova, and E. Mihaylova, "New non-toxic holographic photopolymer material," Journal of Optics, vol. 14, no. 1, Article ID 015601, 2012.

[22] D. Cody, I. Naydenova, and E. Mihaylova, "Effect of glycerol on a diacetone acrylamide-based holographic photopolymer material," Applied Optics, vol. 52, no. 3, pp. 489-494, 2013.

[23] M. Ortuño, E. Fernández, S. Gallego, A. Beléndez, and I. Pascual, "New photopolymer holographic recording material with sustainable design," Optics Express, vol. 15, no. 19, pp. 12425-12435, 2007.

[24] S. Gallego, A. Márquez, M. Ortuño, S. Marini, and J. Francés, "High environmental compatibility photopolymers compared to PVA/AA based materials at zero spatial frequency limit," Optical Materials, vol. 33, no. 3, pp. 531-537, 2011.

[25] A. Olivares-Perez, M. P. Hernández-Garay, I. Fuentes-Tapia, and J. C. Ibarra-Torres, "Holograms in polyvinyl alcohol photosensitized with $\mathrm{CuCl}_{2}\left(2 \mathrm{H}_{2} \mathrm{O}\right)$," Optical Engineering, vol. 50, no. 6, Article ID 065801, 6 pages, 2011.

[26] M. Ortuno, S. Gallego, A. Marquez, C. Neipp, I. Pascual, and A. Belendez, "Biophotopol: a sustainable photopolymer for holographic data storage applications," Materials, vol. 5, pp. 772-783, 2012.

[27] T. Mosmann, "Rapid colorimetric assay for cellular growth and survival: application to proliferation and cytotoxicity assays," Journal of Immunological Methods, vol. 65, no. 1-2, pp. 55-63, 1983.

[28] D. Hughes and H. Mehmet, Cell Proliferation \& Apoptosis, BIOS Scientific, Oxford, UK, 2003.

[29] S. Martin, P. Leclere, Y. Renotte, V. Toal, and Y. Lion, "Characterisation of an acrylamide-based dry photopolymer holographic recording material," Optical Engineering, vol. 33, pp. 3942-3946, 1994.
[30] S. Martin, C. A. Feely, and V. Toal, "Holographic recording characteristics of an acrylamide-based photopolymer," Applied Optics, vol. 36, no. 23, pp. 5757-5768, 1997.

[31] M. S. Mahmud, I. Naydenova, T. Babeva, R. Jallapuram, S. Martin, and V. Toal, "Determination of threshold exposure and intensity for recording holograms in thick green-sensitive acrylamide-based photopolymer," Applied Optics, vol. 49, no. 28, pp. 5276-5283, 2010.

[32] H. Sherif, I. Naydenova, S. Martin, C. McGinn, and V. Toal, "Characterization of an acrylamide-based photopolymer for data storage utilizing holographic angular multiplexing," Journal of Optics A, vol. 7, no. 5, pp. 255-260, 2005.

[33] M. Moothanchery, I. Naydenova, and V. Toal, "Study of the shrinkage caused by holographic grating formation in acrylamide based photopolymer film," Optics Express, vol. 19, no. 14, pp. 13395-13404, 2011.

[34] H. Kogelnik, "Couple wave theory for thick hologram gratings," Bell System Technical Journal, vol. 48, no. 9, pp. 2909-2947, 1969.

[35] J. W. Trevan, "Error of determination of toxicity," Proceedings of the Royal Society of London, vol. 101, no. 712, pp. 483-514, 1927.

[36] E. Hodgson, A Textbook of Modern Toxicology, 82, John Wiley \& Sons, Hoboken, NJ, USA, 2010.

[37] J. C. Kotz, P. Triechel, and J. R. Townsend, Chemistry and Chemical Reactivity, Cengage Learning, Stamford, Conn, USA, 2009.

[38] I. Naydenova, R. Jallapuram, R. Howard, S. Martin, and V. Toal, "Investigation of the diffusion processes in a self-processing acrylamide-based photopolymer system," Applied Optics, vol. 43, no. 14, pp. 2900-2905, 2004. 

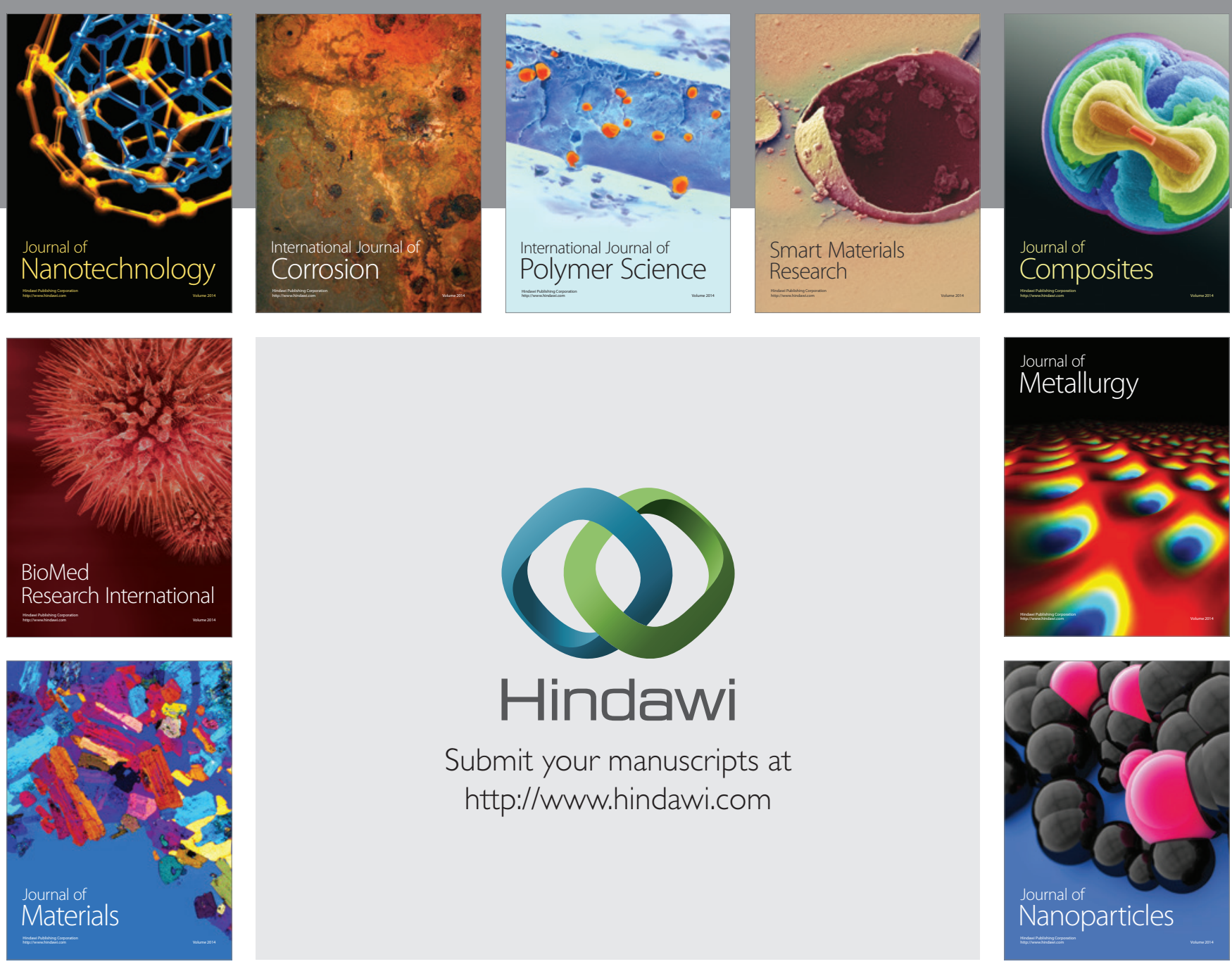

Submit your manuscripts at http://www.hindawi.com
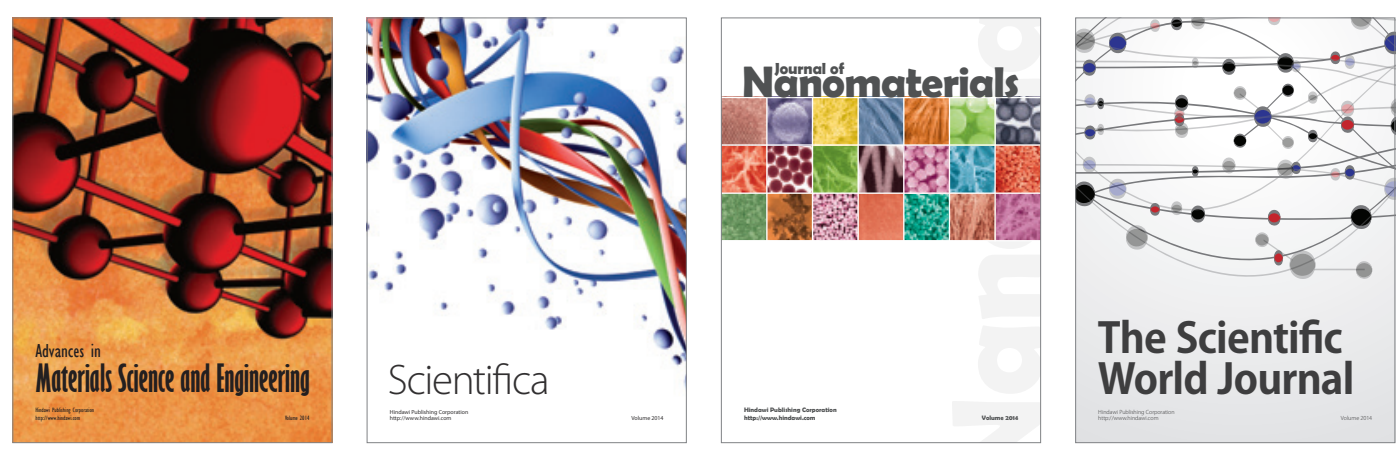

\section{The Scientific World Journal}
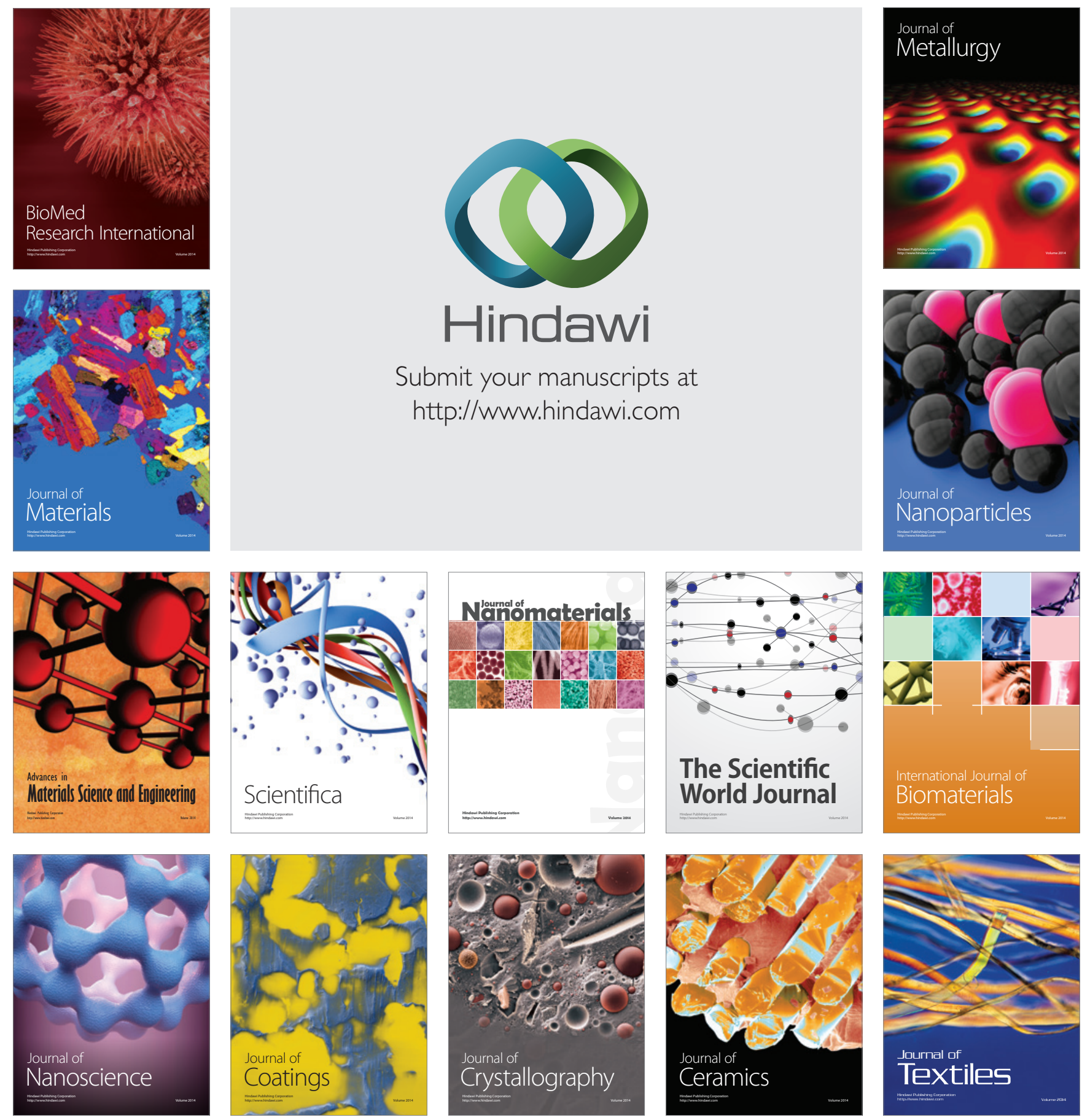